\title{
Development and Implementation of a Pain Education Program
}

\author{
Betty R. Ferrell, Ph.D., F.A.A.N., ${ }^{*}$ Michelle Rhiner, R.N., M.S.N., ${ }^{*}$ \\ and Bruce A. Ferrell, M.D.†
}

Pain is a significant problem for cancer patients and is of particular concern for the elderly. This article reports on the development and implementation of a pain management educational intervention for elderly cancer patients and their family caregivers. This patient education program was developed within a research study funded by the American Cancer Society.

Subjects were stratified as either elderly (60-75 years) or oldest (greater than 75 years) and then were randomly assigned to an experimental group that received the three-part, structured pain education program or a control group that received usual care. Control group subjects were offered the intervention at the conclusion of data collection. The outcomes of the pain education were measured at two times after the intervention. Study variables included patient outcomes such as pain intensity, pain knowledge and attitudes, medication compliance, and quality of life as well as family caregiver outcomes.

This pain education program was developed, implemented, and evaluated in $\mathbf{4 0}$ patients and family caregivers in the first year of a 2-year project. In this article, the investigators present the development and structure of the three-part education program, general principles of patient education regarding pain, methods of evaluating pain education, and initial results of the pain education.

Pain education includes basic principles of pain relief, pharmacologic interventions, and nondrug interventions for relief of pain. This program has demonstrated that both cancer patients and their family caregivers benefit from a structured education program for relief of cancer pain. Cancer 1993; 72:3426-32.

Presented at the Second National Conference on New Oncologic Agents: Practical Applications, San Diego, California, February 4-6, 1993

From the *City of Hope National Medical Center, Duarte, California, and $\nmid$ Sepulveda Veterans Administration Hospital and University of California, Los Angeles, California.

Funded by a research grant from the American Cancer Society.

Address for reprints: Betty Ferrell, Ph.D., F.A.A.N., City of Hope National Medical Center, 1500 East Duarte Road, Duarte, CA 91010.

Accepted for publication July 30, 1993.
Key words: pain, cancer pain, pain education, elderly/ cancer, patient education.

Pain is a significant problem affecting $50-80 \%$ of cancer patients and disturbing overall quality of life. ${ }^{1}$ Pain is a special concern in elderly patients and yet has gone understudied in both oncology and geriatrics. Pain interrupts physical and psychological well-being, interferes with role function and relationships, and is related to other physical symptom disturbance. Pharmacologic and nonpharmacologic interventions are available to treat pain, yet an estimated $80 \%$ of patients with cancer pain are not well controlled. ${ }^{2}$ With an increase in outpatient care, patients and families are assuming the responsibility for pain management at home. Research is needed to advance our knowledge of pain assessment and management in the vulnerable population of elderly cancer patients.

The problem of cancer pain has emerged as a major health care priority in the 1990 s. Pain has been identified by the World Health Organization as an international priority. The National Cancer Institute has also designated the relief of cancer pain as a high priority for professional education and research. Professional organizations such as the Oncology Nursing Society and the American Society of Clinical Oncologists have initiated assertive efforts to address the problem of cancer pain. These efforts have resulted in outcomes such as the Oncology Nursing Society position paper on cancer pain $^{3}$ and the recently developed policy statement and formal pain curriculum for oncology fellowship programs developed by the American Society of Clinical Oncologists.

The American Cancer Society has also demonstrated a commitment to eradicating the undertreatment of cancer pain through designation of pain as a chief priority for 1993. A final important element is the forthcoming clinical guidelines for the treatment of chronic cancer pain in progress by the Agency for Health Care Policy and Research. 
The emphasis of these organizational efforts has largely focused on the problem of cancer pain and educational needs of health care providers. Efforts by the growing network of state pain initiatives has also begun to address the many regulatory barriers to accessing pain medications. Regulatory response to drug abuse and the "Just Say $\mathrm{No}^{\prime \prime}$ mentality have had a serious impact on the prescribing of analgesics for cancer patients. While most of the efforts and the existing literature acknowledge the importance of patient education regarding pain, there are in fact few examples of structured pain education programs for patients in pain or their family caregivers. The importance of patient education has long been recognized by both the American Cancer Society and the National Cancer Institute as a key element in comprehensive cancer care.

\section{Review of Literature}

The World Health Organization estimates that 3.5 million people suffer from cancer-related pain each day. ${ }^{1}$ Pain significantly interrupts the integrity and quality of life for cancer patients. Pain is associated with decreased function $^{11}$ and patients in chronic pain are immobilized by symptoms, experience a decreased level of daily activity, and have disruption in sleep, interpersonal relationships, and appetite. Pain is cited as an overwhelming and all-consuming experience for patients and their care providers.

Pain research has also focused on the examination of pharmacologic and nonpharmacologic modes of pain relief. This research has contributed to advancement of analgesic use and to alternate forms of pain relief. ${ }^{4,5}$ Research related to attitudes and behaviors of health care providers in the management of cancer pain has identified misconceptions and behaviors of health professionals that have inhibited adequate pain management for the chronic pain associated with cancer. ${ }^{6,7}$

In our review of 2985 citations in Index Medicus during 1989, which included "pain" as a title or index term, only 49 citations (1.6\%) included "family," "home," or "caregivers" as indexing terms. Pain has also been understudied in the elderly, especially as it relates to caregiver burden, elder neglect, and abuse. In our review of 11 leading textbooks of geriatric medicine, only two had chapters devoted to pain. Similarly, in our review of eight geriatric nursing textbooks totalling more than 5000 pages of text, less than 18 pages were devoted to discussion of pain. ${ }^{8}$

Available research is singularly concerned with the management and experience of cancer pain in the inpatient setting. Health care providers manage pain in the hospital and they are often unfamiliar with the experi- ence of pain outside this setting and the management of pain by patients themselves. This lack of understanding is of particular significance in light of the current trend toward outpatient management of cancer patients and in home health care as the setting for much of oncology nursing.

Cancer is a disease affecting older adults and this trend will continue because of increased long-term survival and an aging population. The need for pain research specific to the elderly is heightened by special characteristics of this population. Elderly patients disproportionately suffer from chronic painful conditions and have sensory impairments complicating pain assessment. ${ }^{9}$ Older patients often have multiple diagnoses and complex symptoms that may complicate the pain experience. This population is also known to have limited social and financial resources that reduce access to health care.

Pain is a multidimensional concept related to a number of associated symptoms. Physical symptoms such as fatigue or constipation, mood states, and overall quality of life are influencing variables in the patient's experience of pain. Pain has been associated with chronic depression, anxiety, stress, and fear. Physical symptoms frequently accompanying chronic pain include nausea, fatigue, insomnia, weight loss, immobility, and constipation.

The relationship between pain and quality of life has been alluded to in the literature and was specifically analyzed by the investigators' previous research. ${ }^{10-12}$ One of the interesting findings in this research was that cancer patients without pain demonstrated an improved overall quality of life as compared to patients with pain.

Most patients are treated within more traditional programs or are treated solely by family members at home. Pain experts agree that, in fact, it is the combination of drug and nondrug strategies that provides the best pain management. Nonpharmacologic pain management strategies have also been implemented largely based on anecdotal reports. Advances in pain management have strongly supported the combination of drug and nondrug strategies for pain relief citing a variety of methods including transcutaneous nerve stimulation, biofeedback, music therapy, hypnosis, and other nonpharmacologic treatments. ${ }^{13-15}$

Frequently cited barriers to effective pain management by patients include fears of respiratory depression, fear of drug tolerance, fear of drug addiction, and lack of knowledge about chronic pain. ${ }^{16,17}$ It has recently been documented that family members play an important role in pain management. ${ }^{18-20}$ This is increasingly true as patients are being cared for in the home by 
family members. Advances in pain technology now require that families manage complex medication regimens, parenteral infusion devices, and even epidural catheters in the home.

Our recently concluded study of family factors influencing pain management identified the critical role of family caregivers in pain management. Caregivers reported extreme fears of the patient becoming addicted to pain medications and they feared respiratory depression and drug tolerance. In response to their concerns caregivers tended to undermedicate the patient. They expressed feelings of helplessness in being unable to provide comfort for the patient. ${ }^{18-20}$

One of the major contributions to pain education has been the work of Rimer, et al. at Fox Chase Cancer Center. These investigators have identified the importance of patient education in cancer pain control and identified five phases of education including assessment, goal setting, selection of educational strategies, implementation, and reassessment. ${ }^{21}$ In previous research, these investigators explored the learning needs of patients in pain ${ }^{22}$ and then demonstrated in an intervention study the impact of pain education on patient adherence, side effects, concerns about addiction and tolerance, and pain intensity. ${ }^{23}$

\section{Program Development and Implementation}

Development of the program materials for this pain education study was based on review of existing materials and literature and input from pain consultants. The teaching materials developed included the content for the verbal instruction by the nurse in the home for the three-part intervention, a written patient education booklet, two audiocassette tapes, and written instructions for 19 interventions across 5 areas of nondrug techniques including heat, cold, massage, relaxation/ distraction, and imagery.

As with any patient education materials, sensitivity to the needs of the subjects was important. For example, the few patient booklets available on the topic of pain were generally quite long (more than 40 pages) and printed in smail type. The booklet developed for this study is 10 pages long and printed in larger type with illustrations.

Audiocassette tapes were produced and left with the patient at the conclusion of each of the first two education sessions. The tapes were provided so that the patient can listen to the information repeatedly to reinforce the instruction. It is widely accepted that patients remember only a fraction of the information provided and that information must be reinforced to be retained.
The tapes are played on a small tape player with headphones.

Written instruction were also developed for each of the 19 nondrug interventions. These instruction sheets contain information about the method, why it is helpful for pain, instructions for use, and any precautions (e.g., contraindications for the use of heat).

Equipment was selected for each of the 19 nondrug interventions and costs were compared to determine the best source for obtaining the products. Methods of heat included use of dry heating pads, moist heating pads, hot wraps, hot packs, hot water bottles, and hot tub baths. Cold methods included ice massage, ice packs, ice wraps, rotating ice cloths, and menthol combined with ice. Massage methods included two forms of electric massagers with various attachments as well as instruction regarding hand massage.

Distraction techniques included the use of music and humor through audiocassettes based on the patient's preferences. Relaxation included audiotaped, progressive muscle relaxation with deep breathing, and audio stimulation (simulated nature sounds). A guided imagery tape was also developed that is focused on relief of pain.

Once selected for the study and after informed consent is obtained, the subjects were randomly assigned to either the experimental or control groups. The control group subjects were given a copy of the written instruction book. Subjects were instructed on the use of the self care log to document their pain experience and the interventions they use to relieve their pain.

The experimental group subjects received a threepart pain instruction. Part I included general information about pain. Topics covered included an overview of pain, assessment of pain, and the need to relieve pain to promote overall comfort and quality of life. Part II focused on pharmacologic interventions including principles of drug addiction and drug tolerance, prevention of pain through routine scheduling, and treatment of associated symptoms. Part III included information about nondrug management of pain and demonstration of nondrug pain management techniques. General principles of nondrug pain management were presented. Nondrug interventions were presented as useful adjuncts to medication and a combination of drug and nondrug interventions provided optimum pain relief. A maximum of $\$ 50$ per patient was allotted to purchase the nondrug intervention equipment. A summary of the teaching content across the three visits is provided in Table 1.

Caregivers who were included in the study were asked to be present for the three intervention visits. Caregivers are included in all the teaching provided by 
Table 1. Pain Education Program Content

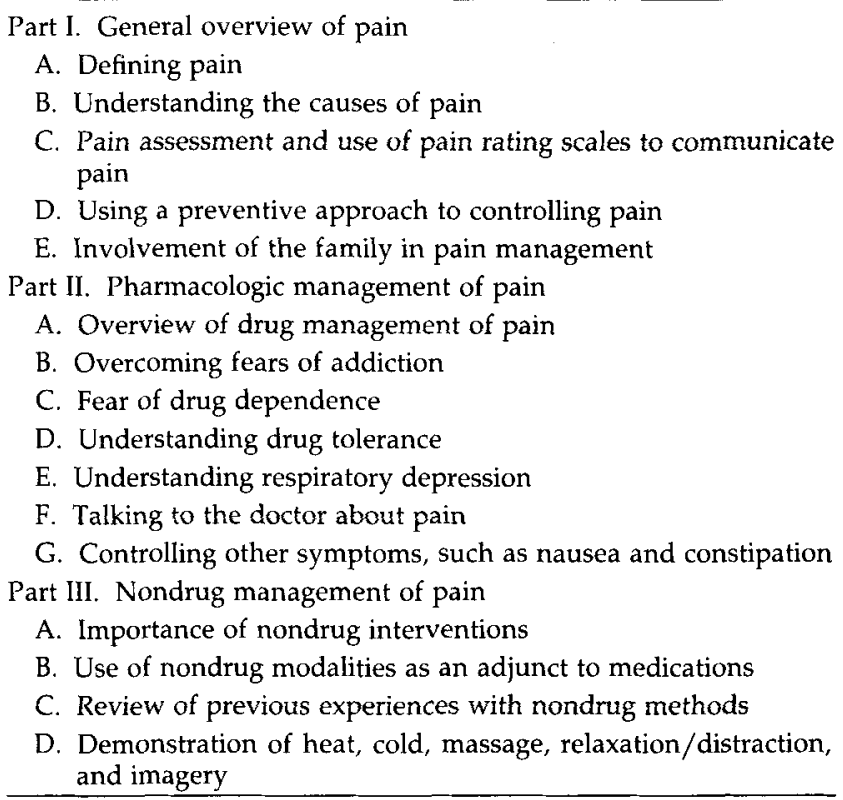

the nurse and are actively included in all nondrug interventions. For example, caregivers were instructed in their role in supporting the patient to use routine analgesia to prevent pain and were coached in participating in massage or relaxation exercises.

The primary physician was contacted when the patient was entered into the study and as needed to discuss medication orders. Any medication changes or other medical treatments that occurred were recorded by the research nurse or the patient on the self care log.

The development of the pain education program across these three areas has provided a framework to provide a comprehensive approach to pain relief. Table 2 includes a summary of important teaching principles applied to pain education based on patient education literature. $^{24-26}$

\section{Program Evaluation}

The impact of the pain education program was evaluated by the use of several established measures. All experimental subjects received two follow-up home visits at 1 week and 4 weeks postinstruction. Control subjects received two evaluation visits, which corresponded to the experimental subjects' time in the study. These visits were intended to collect data that measured the outcomes of the intervention. All control group subjects were offered the three-part intervention at the conclusion of data collection and to date, all subjects have opted to participate in the education program.
The study instruments were selected to provide multiple measures while realizing the physical limitations of the subject in pain. A quality of life tool was used to measure the outcomes in the quality-of-life domains of physical well-being (i.e., fatigue, sleep, strength), symptoms (i.e., nausea, vomiting, bowel management), psychological well being (i.e., happiness, worry over illness, unfinished business), and social concerns (i.e., relationships, intimacy). This scale provided an efficient measure of multiple variables. It also includes an item assessing perception of overall quality of life and items measuring pain distress and pain intensity. It was developed and used extensively by the coinvestigators during the past 8 years.

\section{Table 2. Teaching Principles for Pain Education}

Information provided must be accurate and current. Content should be reviewed by experts in the area and pilot tested in a sample of patients.

Teaching should be preceded by establishing what the patient already knows about his/her condition/pain management.

Establish goals and objectives with the patient/family to enhance cooperation and compliance with the recommended plan of treatment. Information should be immediately useful when teaching adults.

Teach the smallest amount possible rather than overload patients who are already burdened by illness and pain. The patient must know enough about his/her condition to understand the rationale behind the regimen and be able to carry out the desired behavior.

Use a combination of education methods, such as written materials, lecture, discussion, and audiovisual tools.

Keep the teaching session brief with breaks as needed by the patient.

Present the most important material first. For example, it may be necessary to first overcome the patient's overwhelming fear of addiction before he/she will be at all open to drug management of pain.

The appropriate materials must be selected to convey the message/ information to be taught. Can existing materials be used or is it necessary to produce new materials?

Readability of written materials should be appropriate for the cognitive level of the patient. In general, no higher than a sixth grade reading level is recommended. A readability index should be performed on all written information.

Written materials should be in a larger print for elderly patients.

Reinforce written information with an audiocassette tape that can be replayed as often as necessary.

Illustrations and written materials should be clear and concise. Avoid medical jargon.

Repetition is necessary. Encourage questions. Ask questions. Have the patient/family state what they have learned in their own words.

Whenever possible, involve family and supportive friends in the educational program.

Choose an environment that is quiet with a temperature that is comfortable for the patient and family. The patient should be physically comfortable to learn.

Education must be individualized with consideration of cultural influences. 


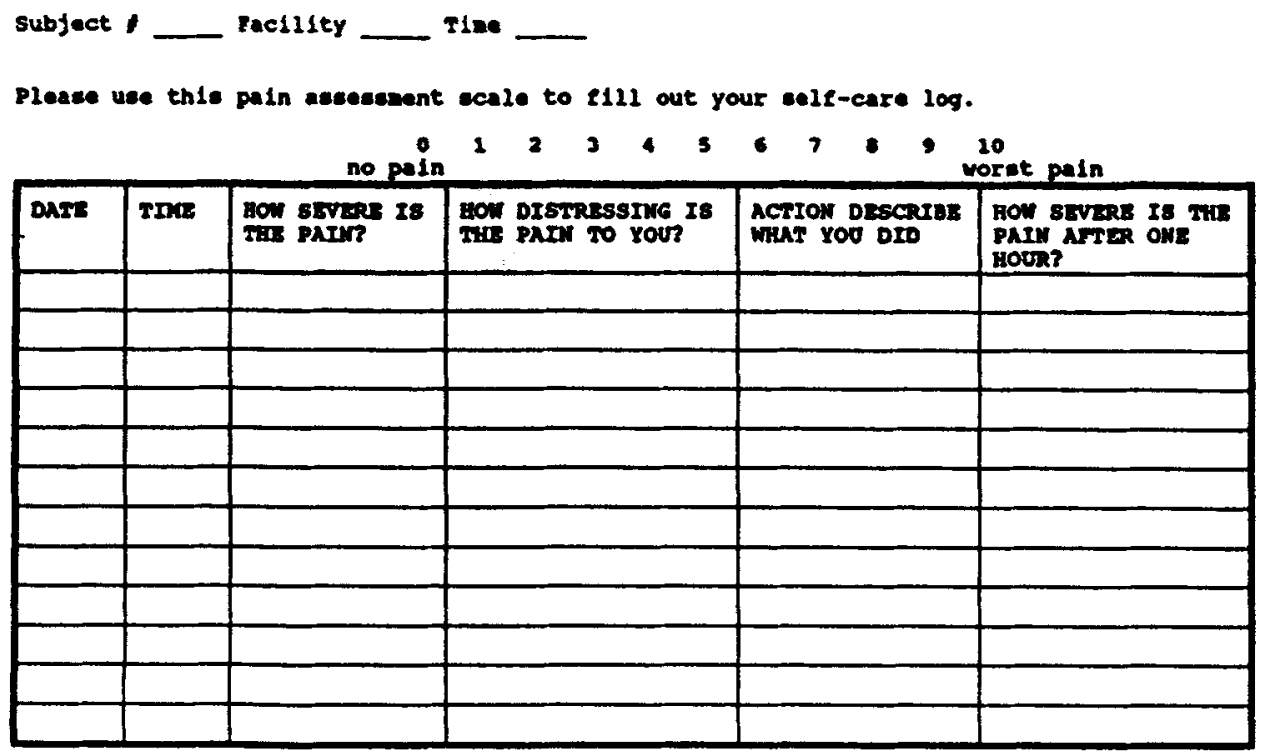

Figure 1 . Self care $\log$ for measuring compliance with the drug and nondrug interventions and perceived effectiveness of the interventions.
Compliance with the drug and nondrug interventions and perceived effectiveness of the interventions was measured by use of a self care $\log$ (Fig. 1). This log was based on the extensive work by Dodd (unpublished observations $)^{27}$ using self care logs in research related to chemotherapy. Subjects record any actions taken to relieve their pain. Compliance with drug interventions is calculated using a percent of the amount of drug prescribed divided by the amount of drug taken. The nondrug interventions are calculated by the frequency of nondrug interventions used. Perceived effectiveness is based on the subject's ratings to be recorded 1 hour after any action, either taking a medication or doing a nondrug intervention such as relaxation.

Mood is measured using the profile of mood states. ${ }^{28}$ The profile of mood states has been used extensively in cancer research. The subscales include tension-anxiety, depression-dejection, anger-hostility, confusion-bewilderment, vigor-activity, and fatigueinertia.

The patient pain questionnaire was developed to measure the knowledge and attitudes of the caregiver and patient in managing pain. The tool consists of a 21-item visual analog scale measuring knowledge and attitudes across the domains of knowledge about pain medication, knowledge of pain principles, perceptions / experiences with the patient's pain, and caregiver roles in pain relief.

Parallel versions of the profile of mood states, the quality of life tool and patient pain questionnaire are used to measure outcomes of family caregivers. Additionally, a caregiver burden tool is used to evaluate the impact of pain management on family caregivers. ${ }^{29}$
Caregiver burden has been discussed in the geriatric literature in illnesses such as Alzheimer's disease that require caregiver involvement but has not been addressed widely in the oncology literature.

The instruments were selected based on review of the geriatric and pain literature as well as on our own clinical practice and research in pain in the elderly. The instruments were selected to minimize subject burden while measuring the multidimensional outcomes of pain and its management. Figure 2 shows the overall study design including the intervention and evaluation.

\section{Initial Results}

The 40 subjects completing the study in the first year had a mean age of 66 years. These elderly patients have a low income with $43 \%$ of subjects having an annual household income of less than $\$ 10,000$ and $95 \%$ having an income less than $\$ 30,000$. Twenty-two percent are ethnic minorities with the Hispanic population predominating. The major cancer diagnoses were prostate $(17 \%)$, colon (12\%), lung (12\%), and breast $(19 \%)$. The average time since cancer diagnosis was 53 months and the average time since their pain began is 16 months. These figures are significant in recognizing that patients and families endure cancer pain of long duration.

Initial analysis of medication use revealed that many of these patients are receiving small doses of weak medications and that the patients are taking only $70 \%$ of the medications prescribed by their physicians (based on oral morphine equivalents). Most of these patients were not using any nondrug interventions before this study. 


\section{Subject Selection and Random Assignment}

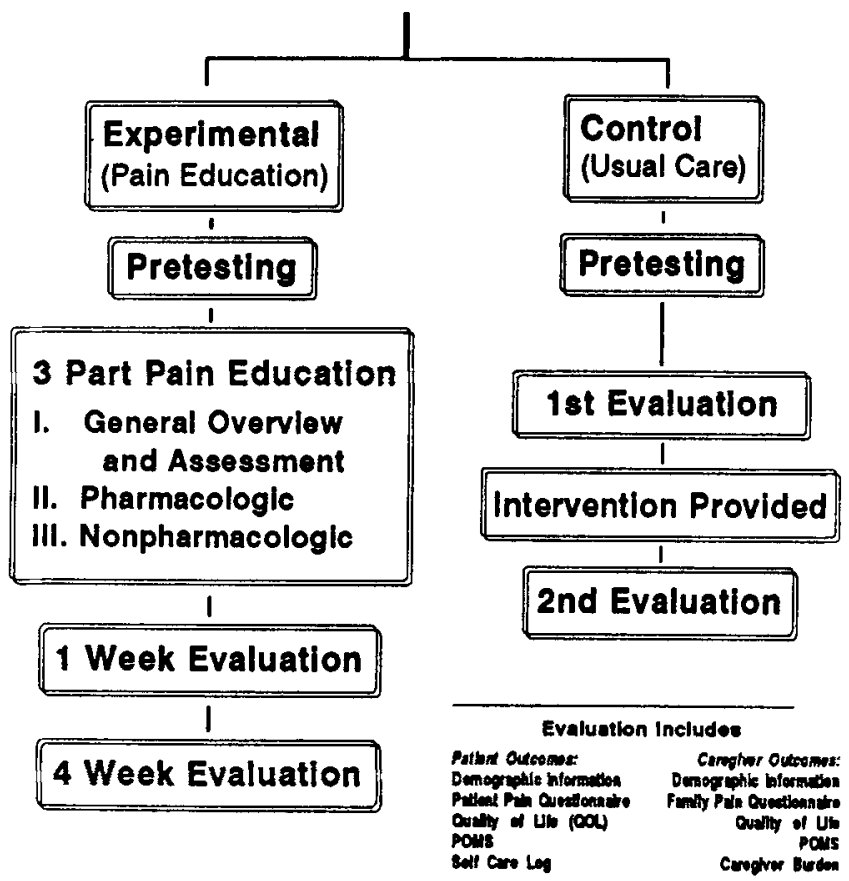

Figure 2. Overall study design including the intervention and evaluation.

Preliminary analysis of patient outcomes using dependent $t$ tests indicated the pain education program to be effective in decreasing pain intensity $(P=0.05)$, decreasing perception of pain severity $(P=0.001)$, decreasing fear of addiction $(P=0.02)$, decreasing anxiety $(P=0.05)$, and increasing the use of pain medications $(P=0.01)$. Patients reported improved sleep $(P=0.03)$ and increased knowledge levels regarding pain principles such as the use of medications on a schedule rather than on an as-needed basis $(P=0.007)$. The patients were very positive about the use of the nondrug interventions and eagerly participated in that session. The use of heat and massage were the primary modalities used but each of the five areas of nondrug treatments was employed with success.

Data from the initial 29 caregivers revealed that their mean age was 60 years and most caregivers were either the spouse $(60 \%)$ or adult child of the patient $(27 \%)$. Seventy-six percent $(76 \%)$ of family caregivers were women. Fifty-five percent of family caregivers were also employed. Initial analysis also revealed significant differences in caregiver outcomes in areas such as improved knowledge, reduced fear of addiction, giving adequate doses of medications, medicating around the clock rather than as-needed, and decreased fear of respiratory depression.

\section{Clinical Implications}

This patient education program combines the components of basic pain principles, pharmacologic management, and nondrug interventions. The educational program involves family caregivers and was designed to be generalizable across clinical settings at a minimal cost.

Advances in cancer pain relief are long overdue in oncology practice. The widespread attention by professional societies, guidelines from cancer organizations, and advances in pain research are to no avail unless they reach the patients experiencing pain and those family members who care for them.

\section{References}

1. World Health Organization. Cancer pain relief monograph. Geneva: WHO, 1986.

2. Bonica J. Treatment of cancer pain: current status and future needs. Pain 1984; 2(Suppl); S196.

3. Spross J, McGuire D, Schmitt R. Oncology Nursing Society position paper on cancer pain. Oncol Nuts Forum 1991; 17:595-614, 751-760, 943-944.

4. Melzack R, Wall P. The challenge of pain. New York: Basic Books, 1982.

5. Cleeland C. Barriers to the management of cancer pain. Oncology 1987; 1(Suppl. 2):19-26.

6. McCaffery M, Ferrell BR. Opioid analgesics: nurses' knowledge of doses and psychological dependence. J Nurs Staff Devel 1992; March/April:77-84.

7. Ferrell BR, McGuire D, Donovan M. Knowledge and beliefs of nursing faculty regarding pain. J Prof Nurs 1993; 9(2):79-88.

8. Ferrell BA, Ferrell BR. Pain in the nursing home. J Am Geriatr Soc $1990 ; 38: 409-14$.

9. Harkins SW, Kwentus J, Price DD. Pain and suffering in the elderly. In: Bonica JJ, editor. Management of pain. Philadelphia: Lea \& Febiger, 1990: 552-9.

10. Ferrell BR, Wisdom C, Wenzel C. Quality of life as an outcome variable in the management of cancer pain. Cancer 1989; 63:2321-7.

11. Padilla G, Ferrell BR, Grant MM, Rhiner M. Defining the content domain of quality of life for cancer patients with pain. Cancer Nurs 1990; 13:108-15.

12. Ferrell BR, Wisdom C, Wenzl C, Brown J. Controlled release vs short acting analgesia: effects on pain and quality of life. Oncol Nurs Forum, 1989; 26:521-6.

13. Bond MR. Physiologic and psychiatric techniques for the relief of pain in advanced cancer. In: Bonica J, Ventafridda V, editors. Advances in pain research and therapy. Vol. 2. New York: Raven Press, 1979:81-8.

14. McCaffery M, Beebe A. Pain: clinical manual for nursing practice. St. Louis: Mosby, 1989.

15. Turk D, Reldman C. Noninvasive approaches to pain control in terminal illness: the contribution of psychological variables. Hospice J 1992; 8(1/2):1-23.

16. McGuire D, Yarbro C. Cancer pain management. New York: Grune \& Stratton, 1987.

17. Parkes $\mathrm{CM}$. Home or hospital? Terminal care as seen by surviving spouses. J R Coll Gen Pract [Occas Pap] 1978; 28:19-30.

18. Ferrell BR, Ferrell BA, Rhiner M, Grant MM. Family factors influencing cancer pain. Postgrad Med J 1991; 67(Suppl 2):S64S69. 
19. Ferrell BR, Rhiner M, Cohen M, Grant M. Pain as a metaphor for illness. Part I: impact of cancer pain on family caregivers. Oncol Nurs Forum 1991; 18:1303-9.

20. Ferrell BR, Cohen M, Rhiner M, Rozak A. Pain as a metaphor for illness. Part II: family caregivers' management of pain. Oncol Nurs Forum 1991; 18:1315-21.

21. Rimer BK, Kedziera P, Levy MH. The role of patient education in cancer pain control. Hospice J 1992; 8(1/2):171-91.

22. Rimer B, Levy M, Keintz MK, MacElwee N, Engstrom, PF. Improving cancer patients' pain control through education. In: Engstrom PF, Mortenson LE, Anderson PN, editors. Advances in cancer control: the war on cancer- 15 years of progress. New York: Alan R Liss, 1987: 123-7.

23. Rimer B, Levy MH, Keintz MK, Fox L, Engstrom PF, MacElwee $N$. Enhancing cancer pain control regimens through patient education. Patient Educ Counsel 1987; 10:267-277.
24. National Cancer Institute. Making health communications programs work: a planner's guide. Bethesda, MD: Office of Cancer Communications, The Institute, NIH pub. no. 89-1493, 1989.

25. Meade C, Diekmann J, Thornhill D. Readability of american cancer society patient education literature. Oncol Nurs Forum 1992; 19:51-5.

26. Morra ME. Teaching strategies: the public. In: Groenwald SL, Frogge $\mathrm{MH}$, Goodman $\mathrm{M}$, Yarbro $\mathrm{CH}$, editors. Cancer nursing principles and practice. 2nd ed. Boston: Jones and Bartlett Publishers, 1990: 1246-55.

27. Dodd, M. Measuring informational intervention for chemotherapy and self-care behavior. Res Nurs Health 1984; 7:43-50.

28. McNair DM, Lorr M, Dropplemen LF. Profile of mood states. San Diego: EDITS, Educational and Testing Service, 1971.

29. Robinson B. Validation of a caregiver strain index. J Gerontol $1983 ; 38: 344-88$. 